\title{
FAKTOR-FAKTOR YANG BERHUBUNGAN DENGAN KONSUMSI TABLET TAMBAH DARAH PADA IBU NIFAS DI WILAYAH KERJA PUSKESMAS MUTIARA BARAT TAHUN 2019
}

\author{
Fatmini $^{1}$, Heru Santoso ${ }^{2}$, Kesaktian Manurung ${ }^{3}$, Rosdiana $^{4}$ \\ ${ }^{1}$ Program Studi Magister Kesehatan Masyarakat, Universitas Sari Mutiara Medan \\ Email :fatmini.gadis@gmail.com \\ ${ }^{2}$ Fakultas Kesehatan Masyarakat, Universitas Sumatera Utara \\ Email : heru_php@yahoo.com \\ ${ }^{3}$ Universitas Sari Mutiara Medan \\ Email : kesaktianmanurung56@gmail.com \\ ${ }^{4}$ Balai Litbangkes Aceh \\ Email : rosdianaedwar@gmail.com
}

\begin{abstract}
ABSTRAK
Anemia masih menjadi permasalahan di dunia terutama di negara-negara berkembang. Kondisi ini dapat memberikan dampak merugikan di setiap kelompok umur termasuk ibu hamil. Pada ibu hamil, kejadian anemia dapat menyebabkan penyulit pada ibu maupun bayi yang dikandungnya seperti perdarahan yang mengancam jiwa, keguguran, berat badan bayi lahir rendah dan kelahiran prematur. Tujuan dari penelitian ini adalah untuk mengetahui hubungan faktor paritas, anemia, kunjugan ANC, status gizi dan peran petugas kesehatan dengankonsumsi tablet tambah darah pada ibu nifas di wilayah kerja Puskesmas Mutiara Barat tahun 2019. Jenis penelitian ini adalah penelitian analitik korelasi dengan metode cross sectional. Populasi dalam penelitian ini adalah seluruh ibu hamil trimester III yang terdata di Puskesmas Mutiara Barat pada bulan Januari 2019 sebanyak 139 orang dan sampel merupakan total populasi yaitu 139 responden. Data dianalisis menggunakan uji statistik chi square yang meliputi analisis univariat, bivariat dan multivariat. Hasil penelitian diperoleh: ada hubungan antara paritas $(\mathrm{p}=0,000)$, anemia $(\mathrm{p}=0,016)$, kunjungan $\mathrm{ANC}(\mathrm{p}=0,015)$, status gizi $(\mathrm{p}=0,021)$ dan peran petugas $(\mathrm{p}=0,000)$ dengan konsumsi tablet tambah darah pada ibu nifas. Faktor yang dominan berhubungan dengan konsumsi tablet tambah darah adalah peran petugas. Dari hasil penelitian yang diperoleh diharapkan Puskesmas dapat meningkatkan pengetahuan ibu tentang tablet tambah darah melalui penyuluhan sehingga dapat mempengaruhi sikap para ibu hamil untuk berperilaku mengkonsumsi tablet tambah darah.
\end{abstract}

Kata Kunci: anemia; konsumsi tablet tambah darah; kunjungan ANC paritas; peran petugas; status gizi

\section{ABSTRACT}

Anemia is still a problem in the world, especially in developing countries. This condition can have a detrimental impact on every age group including pregnant women. In pregnant women, anemia can cause complications for the mother and the baby she is carrying, such as life-threatening bleeding, miscarriage, low birth weight and premature birth. The purpose of this study was to determine the relationship between parity, anemia, ANC visits, nutritional status and the role of health workers with the consumption of blood-added tablets in post-partum mothers in the work area of the Mutiara Barat Health Center in 2019. This type of research is a correlation analytic study with crosssectional method. The population in this study were all pregnant women in the third trimester who were recorded at the Mutiara Barat Health Center in January 2019 as many as 139 people and the sample was the total population of 139 respondents. Data were analyzed using the chi square statistical test which includes univariate, bivariate and multivariate analysis. The results obtained: there is a relationship between parity $(p=0.000)$, anemia $(p=0.016)$, ANC visits $(p=0.015)$, nutritional status $(p=0.021)$ and the role of officers $(p=0.000)$ with the consumption of tablets with blood added at postpartum mother. The dominant factor related to the consumption of blood-added tablets is the role of the officer. From the research results obtained, it is hoped that the Puskesmas can increase the knowledge of mothers about blood supplemented tablets through counseling so that it can influence the attitude of pregnant women to consume blood supplemented tablets.

Keywords: ANC visit; anemia; consumption of blood added tablets; nutritional status; parity; role of officers 


\section{PENDAHULUAN \\ Latar Belakang}

Mengkonsumsi tablet tambah darah berkaitan dengan anemia. Hal ini dapat dilihat dari pendapat yang menyatakan bahwa melalui konsumsi tablet Fe yang rutin setiap hari dapat mengurangi prevalensi anemia dan mencegah terjadinya anemia pada ibu hamil (Purnadibrata, 2011).

Anemia masih menjadi permasalahan di dunia terutama di negara-negara berkembang. World Health Organization (WHO) mengemukakan bahwa 50\% lebih wanita di dunia menderita anemia. Kondisi inidapat memberikan dampak merugikan di setiap kelompok umur termasuk ibu hamil. Pada ibu hamil, kejadian anemia dapat menyebabkan penyulit pada ibu maupunbayi yang dikandungnya seperti perdarahan yang mengancam jiwa, keguguran, berat badanbayi lahir rendah(BBLR)dan kelahiran prematur (Mithra, etl, 2013).

Program pemberian tablet tambah darah untuk ibu hamil minimal 90 butir selama masa kehamilan merupakan salah bentuk mengatasi masalah anemia yang dirancang oleh pemerintah di Indonesia. Setiap tablet tambah darah mengandung zat besi yang setara dengan $60 \mathrm{mg}$ besi elemental dalam bentuk Ferro Sulfat, Ferro Fumarat atau Ferro Gluconat dan Asam Folat sebesar 0,400 mg (Kemenkes RI, 2014).

Menurut data WHO secara global, kasus anemia sebanyak 1,62miliar orang atau 24,8\% dari populasi. Selanjutnya WHO mengatakan bahwa $40 \%$ kematian ibu di negara berkembang berkaitan dengan anemia dalamkehamilan.Di Indonesia, prevalensi anemia dalam kehamilan masih cukuptinggi yaitu 68\%, sementara berdasarkan Riskesdas pada tahun 2013, 21,7\% penduduk Indonesia dengan kadar hemoglobin yangkurang dari batas normal dengan proporsi 20,6\% di perkotaan dan 22,8\%di pedesaan (Hanung dan Risnawati, 2015).

Jumlah penderita dinegara berkembang diketahui 370 juta wanita yang menderita anemiakarena defisiensi zat besi. Prevalensi rata-rata lebih tinggi pada ibu hamil(51\%) dibandingkan pada wanita yang tidak hamil (41\%). Prevalensi diantara ibu hamil bervariasi dari 31\% di Amerika Selatan hingga 64\% diAsia bagian selatan. Di India sekitar 88\% ibu hamil yangmenderita anemia dan pada wilayah Asia lainnya ditemukan hampir 60\% wanita yang mengalami anemia (Gibney, 2015).

Sementara itu berdasarkan Riskesdas 2018, diketahui bahwa proporsi riwayat Tablet Tambah Darah (TTD) yang diterima dan dikonsumsi selama kehamilan anak terakhir pada perempuan umur 10-54 tahun di Indonesia yang mendapat TTD adalah 87,6\% dengan yang terendah adalah Propinsi Papua (63\%) dan yang tertinggi adalah Propinsi Sulawesi Selatan (91,6\%), sementara jumlah TTD yang didapat< 90 tablet (49\%) dan $\geq 90$ tablet (51\%) (Kemenkes RI, 2019).

Program suplementasi tablet besi diIndonesia telah berlangsung hampir 20tahun lamanya, namun hasilRiskesdas pada tahun 2013 diketahui bahwaprevalensi anemia sebesar 37,1\%. Angkaini mengalami peningkatan dibandingkanhasil Riskesdas di tahun 2007 denganprevalensi anemia sebesar 33,8\%. Anemiadefisiensi besi merupakan masalah umumdan luas dalam bidang gangguan gizi didunia. Upaya pemerintah dalam mengatasianemia defisiensi besi ibu hamil yaituterfokus pada pemberian tablet tambahandarah $(\mathrm{Fe})$ pada ibu hamil. MenurutPeraturan Kementrian Kesehatan Nomor: 88 Tahun 2012 tentang Standar Tablet Tambah Darah Bagi Wanita Usia Subur dan Ibu Hamil dinyatakan bahwa untukmelindungi wanita usia subur dan ibu hamildari kekurangan gizi dan mencegahterjadinya anemia gizi besi maka perlumengkonsumsi tablet tambah darah. Program pemberian tablet besi sangatterkait dengan pelayanan kesehatan padaibu hamil 
(K1-K4) karena diberikan padasaat ibu hamil melakukan kunjungan kepelayanan kesehatan, pemberian tablet besijuga menjadi salah satu syarat terpenuhinyakunjungan ibu hamil K4(Kemenkes RI dan MilleniumChallenge Account,, 2015).

Berdasarkan data yang diperoleh dari Puskesmas Mutiara Barat pada bulan Januari 2019 diketahui ada 267 orang ibu hamil dari berbagai usia kehamilannya dengan latar berbagai latar pendidikan dimana diantaranya beberapa ibu hamil hanya melakukan kunjungan K1 saja namun untuk kunjungan kedua tidak dilakukan lagi dan juga ditemukan hanya melakukan kunjungan K2 saja. Dari studi pendahuluan tergambar untuk sementara bahwa faktor dari konsumsi tablet tambah darah tersebut diantaranya adalah faktor usia kehamilan dan kunjungan ANC. Dari uraian di atas serta hasil studi pendahuluan yang dilakukan membuat peneliti tertarik untuk mengangkat hal tersebut ke dalam suatu penelitian tentang "Faktor-Faktor Yang Berhubungan Dengan Konsumsi Tablet Tambah Darah Pada Ibu Nifas Di Wilayah Kerja Puskesmas Mutiara Barat Tahun 2019”.

\section{METODE PENELITAN}

Jenis penelitian ini adalah penelitiananalitik korelasi dengan metode cross sectional dilakukan di wilayah kerja puskesmas mutiara barat dengan menggunakan data primer dan data skunder. Populasi dalam penelitian ini adalah seluruh ibu hamil trimester III yang terdata di Puskesmas Mutiara Barat pada bulan Januari 2019 sebanyak 139 orang. Sampel dalam penelitian ini sebanyak 139, pengambilan sampel dalam penelitian ini teknik total sampling.

\section{HASIL PENELITIAN DAN PEMBAHASAN}

a.Analisis Univariat

Tabel 1. Distribusi Frekuensi Karakteristik Pada Ibu NifasDi Wilayah Kerja Puskesmas Mutiara Barat Tahun 2019

\begin{tabular}{lccc}
\hline & Karakteristik Responden & n & \% \\
\hline Umur & & \\
$>30$ tahun & 77 & 55,4 \\
$\leq 30$ tahun & 62 & 44,6 \\
Pendidikan & & \\
SMP & & \\
SMA & 35 & 25,2 \\
D3 & 95 & 68,3 \\
S1 & 4 & 2,9 \\
\hline
\end{tabular}

Berdasarkan tabel 1. diketahui bahwa yang berumur $>30$ tahun ada 77responden dan berumur $\leq$ tahun ada 62 responden $(44,6 \%)$. Sementara yang berpendidikan SMP diperoleh 35 responden $(25,2 \%)$, pendidikan SMA 95 responden $(68,3 \%)$, pendidikan D3 4 responden $(2,9 \%)$ dan S1 5 responden $(3,6 \%)$.

Tabel 2.Distribusi Frekuensi Konsumsi Tablet Tambah DarahPada Ibu Nifas Di Wilayah Kerja Puskesmas Mutiara Barat Tahun 2019

\begin{tabular}{lccc}
\hline \multicolumn{2}{c}{ Konsumsi Tablet Tambah Darah } & n & \% \\
\hline Sesuai & & 122 & 87,8 \\
Tidak Sesuai & Total & 17 & 12,2 \\
\hline & & 139 & 100 \\
\hline
\end{tabular}


Berdasarkan data pada tabel 2. diketahui bahwa konsumsi tablet darah pada kategori sesuai ada 122 responden $(87,8 \%)$ dan yang tidak sesuai ada 17 responden $(12,2 \%)$.

Tabel 3. Distribusi FrekuensiParitasPada Ibu NifasDi Wilayah Kerja Puskesmas Mutiara Barat Tahun 2019

\begin{tabular}{lccc}
\hline & Paritas & n & \% \\
\hline Paritas 1 & & 26 & 18,7 \\
Paritas $2-3$ & & 102 & 73,4 \\
Paritas $>3$ & & 11 & 7,9 \\
\hline & Total & 139 & 100 \\
\hline
\end{tabular}

Berdasarkan data pada tabel 3.diketahui bahwa paritas 1 diperoleh 26 responden $(18,7 \%)$, paritas 2 - 3 ada 102 responden $(73,4 \%)$, paritas $>3$ ada 11 responden $(7,9 \%)$.

Tabel 4. Distribusi Frekuensi Anemia Pada Ibu Nifas Di Wilayah Kerja Puskesmas Mutiara Barat Tahun 2019

\begin{tabular}{lccc}
\hline & Anemia & $\mathbf{n}$ & \% \\
\hline Tidak anemia & & 106 & 76,3 \\
Anemia & & 33 & 23,7 \\
\hline & Total & 139 & 100 \\
\hline
\end{tabular}

Berdasarkan data pada tabel 4. diketahui bahwa 106 responden $(76,3 \%)$ yang tidak anemia sedangkan 33 responden $(23,7 \%)$ yang anemia.

Tabel 5. Distribusi FrekuensiKunjungan ANCPada Ibu NifasDi Wilayah Kerja Puskesmas Mutiara Barat Tahun 2019

\begin{tabular}{lccc}
\hline & Kunjungan ANC & n & \% \\
\hline Baik & & 100 & 71,9 \\
Kurang & & 39 & 28,1 \\
\hline & Total & 139 & 100 \\
\hline
\end{tabular}

Berdasarkan data pada tabel 5. diketahui bahwa responden dengan kunjungan ANC yang baik diperoleh 100 responden $(71,9 \%)$ dan responden kunjungan ANC yang kurang diperoleh 39 responden $(28,1 \%)$.

Tabel 6. Distribusi FrekuensiStatus GiziPada Ibu NifasDi Wilayah Kerja Puskesmas Mutiara Barat Tahun 2019

\begin{tabular}{lccc}
\hline & Status Gizi & n & \% \\
\hline Baik & & 105 & 75,5 \\
Kurangbaik & & 34 & 24,5 \\
\hline & Total & 139 & 100 \\
\hline
\end{tabular}

Berdasarkan data pada tabel 6. diketahui bahwa responden dengan status gizi yang baik diperoleh 105 responden $(75,5 \%)$ dan status gizi kurang baik diperoleh 34 responden $(24,5 \%)$. 
Tabel 7. Distribusi FrekuensiPeran PetugasPada Ibu NifasDi Wilayah Kerja Puskesmas Mutiara Barat Tahun 2019

\begin{tabular}{lccc}
\hline & Peran Petugas & n & \% \\
\hline Baik & & 126 & 90,6 \\
Kurang & & 13 & 9,4 \\
\hline & Total & 139 & 100 \\
\hline
\end{tabular}

Berdasarkan data pada tabel 7. diketahui bahwa peran petugas dengan kategori baik diperoleh 126 responden $(90,6 \%)$ dan yang kurang diperoleh 13 responden $(9,4 \%)$.

\section{b.Analisis Bivariat}

Tabel 8. Tabulasi Silang Antara Paritas Dengan Konsumsi Tablet Tambah Darah Pada Ibu Nifas Di Wilayah Kerja Puskesmas Mutiara Barat tahun 2019

\begin{tabular}{|c|c|c|c|c|c|c|c|}
\hline \multirow{3}{*}{ Paritas } & \multicolumn{4}{|c|}{ Konsumsi Tablet Tambah Darah } & \multirow{2}{*}{\multicolumn{2}{|c|}{ Total }} & \multirow{3}{*}{ p value } \\
\hline & \multicolumn{2}{|c|}{ Sesuai } & \multicolumn{2}{|c|}{ Tidak Sesuai } & & & \\
\hline & $\mathbf{n}$ & $\%$ & $\mathbf{n}$ & $\%$ & n & $\%$ & \\
\hline Paritas 1 & 21 & 15,1 & 5 & 3,6 & 26 & 18,7 & \multirow{4}{*}{0,000} \\
\hline Paritas $2-3$ & 95 & 68,3 & 7 & 5,0 & 102 & 73,4 & \\
\hline Paritas $>3$ & 6 & 4,3 & 5 & 3,6 & 11 & 7,9 & \\
\hline Jumlah & 122 & 87,8 & 17 & 12,2 & 139 & 100 & \\
\hline
\end{tabular}

Berdasarkan tabel 8. diketahui bahwa dari 26 responden (18,7\%) dengan paritas 1 yang mengkonsumsi tablet tambah darah dengan kategori sesuai sebanyak 21 responden $(15,1 \%)$ dan berkategori tidak sesuai diperoleh 5 responden $(3,6 \%)$.Kemudian dari 102 responden dengan paritas 2 - 3 yang mengkonsumsi tablet tambah darah dengan kategori sesuai sebanyak 95 responden $(68,3 \%)$. Dari data tersebut menunjukkan bahwa responden dengan paritas 2 yang paling banyak mengkonsumsi tablet tambah darah dibandingkan ibu nifas dengan paritas 3 .

Selanjutnyaditemukan 7 responden (5\%) dengan paritas 2-3 yangtidak sesuai mengkonsumsi tablet tambah dara. Dari ketujuh responden tersebut data menunjukkan 6 responden dengan paritas 2 dan 1 ibu dengan paritas 3 yang tidak sesuai mengkonsumsi tablet tambah darah. Sementara itu dari 11 responden dengan paritas $>3$ ditemukan 5 responden $(3,6 \%)$ yang tidak sesuai mengkonsumsitablet tambah darah. Pada penelitian ini responden dengan paritas $>3$ adalah paritas 4. Berdasarkan hasil uji statistik diperoleh nilai $=0,000$ yang artinya ada hubungan antara paritas dengan konsumsi tablet tambah darah pada ibu nifas di Wilayah Kerja Puskesmas Mutiara Barat tahun 2019.

Tabel 9. Tabulasi Silang Antara Anemia Dengan Konsumsi Tablet Tambah Darah Pada Ibu Nifas Di Wilayah Kerja Puskesmas Mutiara Barat tahun 2019

\begin{tabular}{|c|c|c|c|c|c|c|c|}
\hline \multirow{3}{*}{ Anemia } & \multicolumn{4}{|c|}{ Konsumsi Tablet Tambah Darah } & \multirow{2}{*}{\multicolumn{2}{|c|}{ Total }} & \multirow{3}{*}{ p value } \\
\hline & \multicolumn{2}{|c|}{ Sesuai } & \multicolumn{2}{|c|}{ Tidak Sesuai } & & & \\
\hline & $\mathbf{n}$ & $\%$ & $\mathbf{n}$ & $\%$ & $\mathbf{n}$ & $\%$ & \\
\hline Tidak Anemia & 97 & 69,8 & 9 & 6,5 & 106 & 76,3 & \\
\hline Anemia & 25 & 18,0 & 8 & 5,8 & 33 & 23,7 & 0,016 \\
\hline Jumlah & 122 & 87,8 & 17 & 12,2 & 139 & 100 & \\
\hline
\end{tabular}


Berdasarkan tabel 9. diketahui bahwa dari 106 responden yang tidak anemiaditemukan sebanyak 97 responden $(69,8 \%)$ yang sesuai mengkonsumsi tablet tambah darah dan ditemukan 9 responden $(6,5 \%)$ yang tidak sesuai mengkonsumsi tablet tambah darah. Kemudian dari 33 responden anemia ditemukan yang mengkonsumsi tablet tambah darah sebanyak 25 responden (18\%) dan yangtidak sesuaimengkonsumsi tablet tambah darah diperoleh 8 responden $(5,8 \%)$.

Berdasarkan hasil uji statistik diperoleh nilai $=0,016$ yang artinya ada hubungan antara anemia dengan konsumsi tablet tambah darah pada ibu nifas di Wilayah Kerja Puskesmas Mutiara Barat tahun 2019.Anemia dapat mengakibatkan dampak yangmembahayakan bagi ibu dan janin sehingga untuk mengatasi anemia tersebut perlu mengkonsumsi tablet tambah darah.

Tabel 10. Tabulasi Silang Antara Kunjungan ANC Dengan Konsumsi Tablet Tambah Darah Pada Ibu Nifas Di Wilayah Kerja Puskesmas Mutiara Barat Tahun 2019

\begin{tabular}{|c|c|c|c|c|c|c|c|}
\hline \multirow{3}{*}{ Kunjungan ANC } & \multicolumn{4}{|c|}{ Konsumsi Tablet Tambah Darah } & \multirow{2}{*}{\multicolumn{2}{|c|}{ Total }} & \multirow{3}{*}{$p$ value } \\
\hline & \multicolumn{2}{|c|}{ Sesuai } & \multicolumn{2}{|c|}{ Tidak Sesuai } & & & \\
\hline & $\mathbf{n}$ & $\%$ & $\mathbf{n}$ & $\%$ & $\mathbf{n}$ & $\%$ & \\
\hline Baik & 92 & 66,2 & 8 & 5,8 & 100 & 71,9 & \\
\hline Kurang & 30 & 21,6 & 9 & 6,5 & 39 & 28,1 & 0,015 \\
\hline Jumlah & 122 & 87,8 & 17 & 12,2 & 139 & 100 & \\
\hline
\end{tabular}

Berdasarkan tabel 10. diketahui bahwa dari 100 responden yang melakukan kunjungan ANC dengan baikditemukan sebanyak 92 responden $(66,2 \%)$ yang sesuai mengkonsumsi tablet tambah darah dan ditemukan 8 responden $(5,8 \%)$ yang tidak sesuaimengkonsumsi tablet tambah darah. Kemudian dari 39 responden dengan kunjungan ANC kurang yang mengkonsumsi tablet tambah darah dengan kategori sesuai sebanyak 30 responden $(21,6 \%)$ dan berkategori tidak sesuai diperoleh 9 responden $(6,5 \%)$. Berdasarkan hasil uji statistik diperoleh nilai $=0,015$ yang artinya ada hubungan kunjungan ANC dengan konsumsi tablet tambah darah pada ibu nifas di wilayah kerja Puskesmas Mutiara Barat tahun 2019. Melalui kunjungan ANC, ibu pada masa kehamilan dapat memahami pentingnya mengkonsumsi tablet tambah darah.

Tabel 11.Tabulasi Silang Antara Status Gizi Dengan KonsumsiTablet Tambah Darah Pada Ibu NifasDi Wilayah Kerja Puskesmas Mutiara Barat Tahun 2019

\begin{tabular}{|c|c|c|c|c|c|c|c|}
\hline \multirow{3}{*}{ Status Gizi } & \multicolumn{4}{|c|}{ Konsumsi Tablet Tambah Darah } & \multirow{2}{*}{\multicolumn{2}{|c|}{ Total }} & \multirow{3}{*}{ p value } \\
\hline & \multicolumn{2}{|c|}{ Sesuai } & \multicolumn{2}{|c|}{ Tidak Sesuai } & & & \\
\hline & $\mathbf{n}$ & $\%$ & $\mathbf{n}$ & $\%$ & $\mathbf{n}$ & $\%$ & \\
\hline Baik & 96 & 69,1 & 9 & 6,5 & 105 & 75,5 & \\
\hline Kurang & 26 & 18,7 & 8 & 5,8 & 34 & 24,5 & 0,021 \\
\hline Jumlah & 122 & 87,8 & 17 & 12,2 & 139 & 100 & \\
\hline
\end{tabular}

Berdasarkan tabel 11. diketahui bahwa dari 105 responden dengan status gizi baikyang mengkonsumsi tablet tambah darah dengan kategori sesuai sebanyak 96 responden $(69,1 \%)$ dan berkategori tidak sesuai diperoleh 9 responden $(6,5 \%)$. Kemudian dari 34 responden dengan status gizikurang yang mengkonsumsi tablet tambah darah dengan kategori sesuai sebanyak 26 responden $(18,7 \%)$ dan berkategori tidak sesuai diperoleh 8 responden $(5,8 \%)$.

Selanjutnya dari hasil uji statistik diperoleh nilai $=0,021$ yang artinya ada hubungan antara status gizi dengan konsumsi tablet tambah darah pada ibu nifas di Wilayah Kerja Puskesmas Mutiara Barat tahun 2019.Dampak dari status gizi yang kurang diantaranya kekurangan zat besi sehingga pada masa kehamilan ibu membutuhkan atau mengkonsumsi tablet tambah darah. 
Tabel 12.Tabulasi Silang Antara Peran Petugas Dengan KonsumsiTablet Tambah Darah Pada Ibu Nifas Di Wilayah Kerja Puskesmas Mutiara Barat Tahun 2019

\begin{tabular}{|c|c|c|c|c|c|c|c|}
\hline \multirow{3}{*}{ Peran Petugas } & \multicolumn{4}{|c|}{ Konsumsi Tablet Tambah Darah } & \multirow{2}{*}{\multicolumn{2}{|c|}{ Total }} & \multirow{3}{*}{ p value } \\
\hline & \multicolumn{2}{|c|}{ Sesuai } & \multicolumn{2}{|c|}{ Tidak Sesuai } & & & \\
\hline & $\mathbf{n}$ & $\%$ & $\mathbf{n}$ & $\%$ & $\mathbf{n}$ & $\%$ & \\
\hline Baik & 117 & 84,2 & 9 & 6,5 & 126 & 90,6 & \\
\hline Kurang & 5 & 3,6 & 8 & 5,8 & 13 & 9,4 & 0,000 \\
\hline Jumlah & 122 & 87,8 & 17 & 12,2 & 139 & 200 & \\
\hline
\end{tabular}

Berdasarkan tabel 12. diketahui bahwa dari 126 responden menyatakan peran petugas baikyang mengkonsumsi tablet tambah darah dengan kategori sesuai sebanyak 117 responden $(84,2 \%)$ dan berkategori tidak sesuai diperoleh 9 responden $(6,5 \%)$. Kemudian dari 13 responden menyatakan peran petugas kurang yang mengkonsumsi tablet tambah darah dengan kategori sesuai sebanyak 5 responden $(3,6 \%)$ dan berkategori tidaksesuai diperoleh 8 responden $(5,8 \%)$.

Selanjutnya dari hasil uji statistik diperoleh nilai $=0,000$ yang artinya ada hubungan antara peran petugas dengan konsumsi tablet tambah darah pada ibu nifas di Wilayah Kerja Puskesmas Mutiara Barat tahun 2019.Peran petugas kesehatan sangat penting pada masa kehamilan ibu karena melalui tugas dan tanggung jawab petugas kesehatan, para ibu hamil dapat mengetahui dan memahami pentingnya mengkonsumsi tablet tambah darah.

Berdasarkan hasil Uji regresi logistik pada pemodelan ketiga diketahui bahwa dari variabel paritas, kunjungan ANC dan peran petugas dengan nilai $p$ tertinggi adalah variabel paritas yaitu $p=0,185$ sehingga pada pemodelan selanjutnya tidak diikutsertakan.Pada pemodelan keempat diketahui bahwa variabel kunjungan ANC dengan nilai $\mathrm{p}=0,224$ sehingga variabel yang dominan berhubungandengan konsumsi tablet tambah darah adalah variabel peran petugas $(p=0,000)$.

Peran petugas kesehatan dapat terlihat ketika ibu hamil datan ke fasilitas kesehatan untuk memeriksakan kesehatannya atau janin yang dikandungnya. Hal ini terlihat dari pendapat Sarwono (2012) yang menyatakan bahwa petugas kesehatan berperan aktif di dalam setiap kunjungan ibu hamil, seperti mengenali kehamilan yang berisiko tinggi khususnya anemia kurang gizi, memberikan penyuluhan kesehatan kepada ibu hamil dan berperan dalam proses pengobatan serta penyembuhan penyakit. Demikian pula Potter dan Perry (2007) mengemukakanbahwa peran tenaga kesehatan adalah sebagai komunikator, motivator, fasilitator dan konselor.

Hasil penelitian ini sesuai dengan penelitian Rahmawati (2008) yang menunjukkan bahwa perilaku tenaga kesehatan mempengaruhi kepatuhan ibu hamil dalammengkonsumsitablet Fe. Kepatuhan ibu hamil dapat lebih ditingkatkan lagi apabila petugas kesehatan mampu memberikan penyuluhan, khususnya mengenai manfaat tablet besi dan kesehatan ibu selama kehamilan.

\section{KESIMPULAN DAN SARAN}

Berdasarka hasil penelitian Di Wilayah Kerja Puskesmas Mutiara Barat di dapat ada hubungan Paritas, Anemia, Kunjungan ANC, Status Gizi, Peran Petugas, Konsumsi Tablet Tambah Darah dengan konsumsi tablet tambah darah pada ibu nifas. Faktor yang dominan berhubungan dengan konsumsi tablet tambah darah adalah peran petugas

Adapun saran bagi Puskesmas Mutiara Barat melalui petugas kesehatan dapat meningkatkan pengetahuan ibu tentang tablet tambah darah dengan memberikan edukasi melalui brosur berisikan 
pentingnya mengkonsumsi tablet tambah darah yang disebarkan ke warga-warga khususnya ibu hamil yang dapat menambah pengetahuan sehingga dapat mempengaruhi sikap sssspara ibu hamil untuk berperilaku mengkonsumsi tablet tambah darah.

\section{Ucapan Terimakasih}

Penulis mengucapkan terimaksih kepala puskesmas Mutiara Barat yang telah memberikan izin dan memberikan dukungan terhadap penelitian ini.

\section{REFERENSI}

Gibney, M. K. (2015). Gizi Kesehatan Mayarakat. Jakarta: Penerbit Buku Kedokteran EGC.

Gibney \& Michael J., (2012). Gizi Kesehatan Masyarakat. Jakarta: EGC.

Hanung A, Risnawati, I., (2015). Dampak Anemia Kehamilan Terhadap Perdarahan Post Partum. Jurnal STIKES Muhammadiyah Kudus. Vol. 6, No. 3

Kementerian Kesehatan RI dan Millenium Challenge Account, (2015). Pedoman Program Pemberian dan Pemantauan Mutu Tablet Tambah Darah Untuk Ibu Hamildi Wilayah Program Kesehatan dan Gizi Berbasis Masyarakat Indonesia. Jakarta

Kemenkes RI, (2019). Riskesdas 2018. Jakarta

Mithra, P., Unnikrishnan, B., Rekha, T., Nithin, K., Mohan, K., Kulkarni, Agarwal, D., (2013). Compliance with Iron Folic Acid Among pregnant Women in Urban Area South India. African Health Sciences. 13(4):880-885.

Potter, A., \& Perry. A.G., (2007). Fundamental Keperawatan (4thEd). Jakarta: EGC

Purnadibrata, I.M. (2011). Upaya Pencegahan Anemia Gizi Pada Ibu Hamil. Jurnal Ilmu Gizi 2(2), $118-124$ 